Check for updates

Cite this: RSC Adv., 2018, 8, 16330

Received 29th March 2018

Accepted 26th April 2018

DOI: $10.1039 / \mathrm{c} 8 \mathrm{ra02739k}$

rsc.li/rsc-advances

\section{Green approaches in the synthesis of furan-based diepoxy monomers $\uparrow$}

\author{
Angela Marotta, ${ }^{\text {ab }}$ Veronica Ambrogi, ${ }^{a}$ Pierfrancesco Cerrutic ${ }^{c}$ and Alice Mija (D) *bd \\ Two eco-respectful, one-step synthetic routes for the preparation of a bio-based epoxy monomer derived \\ from furan precursors are developed. The diglycidyl ester products are throughly characterized in terms of \\ structure and thermal properties. Gathered results indicate that the two selected approaches allow the \\ preparation of pure, furanic diglycidyl ester, which represents a viable bio-based alternative to its \\ petrochemical aromatic counterpart.
}

Research on bio-based polymers has been rapidly increasing in past years, pushed by growing environmental and economic concerns, as well as by the uncertainty about future availability of finite petrochemical resources. ${ }^{1}$ Sustainability is a keyword in this process. In this frame, products that are respectful towards the environment, including eco-compatible building blocks and additives, are now researched to replace petroleum-based polymers with those derived from naturally occurring feedstocks..$^{2-4}$ In the field of epoxy resins, this trend is related also to the necessity to find a good candidate to substitute the controversial building block bisphenol A (BPA), a molecule recognized as an endocrine disrupter and reprotoxic substance. ${ }^{5}$ Epoxy resins are very versatile thermosetting polymers, extremely resistant to corrosion, moisture and chemicals, with good adhesive strength toward most materials (wettability) and low shrinkage upon curing. Due to their high glass transition temperatures and excellent mechanical strength, epoxy resins are widely employed in a broad range of applications, such as electronics, structural adhesives, aerospace composites and protective coatings. In the latter application, the use of BPA results in hazard for customers of food and beverage products packed into containers treated with epoxy resins. The effects of human body contamination caused by BPA are diabetes, cardiovascular diseases, altered liver enzymes and reproductive apparatus damages. ${ }^{5}$ For these reasons, this molecule has been banned in many countries for the manufacturing of child products, and in France and Canada from all the materials in direct contact with food. Therefore, the

\footnotetext{
${ }^{a}$ Department of Chemical, Materials and Production Engineering (DICMaPI), University of Naples "Federico II", P. le Tecchio, 80, 80125 Napoli, Italy

${ }^{b}$ Université Côte d'Azur, Université Nice-Sophia Antipolis, Institut de Chimie de Nice, UMR CNRS 7272, 06108 Nice Cedex 02, France. E-mail: Alice.MIJA@unice.fr

'Institute for Polymers, Composites and Biomaterials (IPCB), CNR, Via Campi Flegrei, 34, 80078 Pozzuoli (NA), Italy

${ }^{d}$ RUDN University, 6 Miklukho-Maklaya Street, Moscow, 117198, Russian Federation

$\dagger$ Electronic supplementary information (ESI) available. See DOI: $10.1039 / \mathrm{c} 8 \mathrm{ra} 02739 \mathrm{k}$
}

necessity to find non-toxic and sustainable building blocks to replace BPA in the production of epoxy resins results mandatory. If one considers also the decreasing availability of oilderived feedstock, the research of new molecules is logically focusing on bio-derived chemicals. Epoxidized vegetable oils have been widely studied for their use in epoxy resins preparation, thanks to their characteristics, availability and low cost. $^{6-8}$ Mechanical properties of epoxy resins obtained using these long aliphatic molecules, alone or mixed to aromatic epoxy comonomers, are encouraging. ${ }^{9,10}$ In order to further improve chemical, thermal and mechanical properties of epoxy resins, the presence of significant content of aromatic moieties is required. In this frame, lignin derivatives appear to be the natural substitutes of BPA. However, time- and energyconsuming extraction processes make lignin-based epoxies expensive and barely available. On the other hand, furanic molecules combine aromatic structure and easily available feedstock, such as carbohydrate biomass. Among furanic molecules, furan-2,5-dicarboxylic acid (FDCA) has been labelled in 2004 as "top value added chemical from biomass" from U.S. Department of Energy, and it has been confirmed being a valuable chemical in $2010 .^{11,12}$ FDCA is a commercially available compound obtained by dehydration of hexose polysaccharides and consequent oxidation of the 5-hydroxymethylfurfural (HMF) intermediate. ${ }^{13-18}$ As a matter of fact, FDCA already results to be an excellent substitute of terephthalic acid in the production of polyesters. Polyethylene furanoate (PEF), obtained from polycondensation of FDCA and ethylene glycol, showed up to be a perfect substitute of PET thanks also to the improved barrier properties. ${ }^{19-21}$ Some big companies, indeed nowadays commercialize bottles made of PEF. ${ }^{22}$ Nevertheless, the number of scientific papers reporting on FDCA-based epoxy resins is still limited and their applicability requires optimization. In a recent work, FDCA has been used as linker between two eugenol molecules, which were then epoxidized leading to materials with good heat resistance properties. ${ }^{23}$ Only Deng et al. used FDCA to obtain the corresponding diglycidyl ester, 
with a two-step procedure involving first allylation on the acidic groups with allyl bromide and consequent epoxidation with $\mathrm{m}$ chloroperoxybenzoic acid ( $m$-CPBA) ${ }^{24}$ The long reaction time, reagents and solvents used and the dangerous by-products, especially from an environmental point of view, make this process still complex and only moderately safe. Therefore, the obtainment of epoxy resins from FDCA monomers through simple, scalable and low environmental and human health impact protocols represents still a challenge. Some authors synthesized the diglycidyl etherof furan reacting the 2,5-bis(hydroxymethyl) furan with epichlorohydrin. ${ }^{25-27}$

In this paper, two new single-step synthetic routes are proposed for the obtainment of bis(oxiran-2-yl-methyl)furan2,5-dicarboxylate (BOFD), starting from FDCA or from and its dimethyl ester (DM-FDCA), respectively.

In the first synthetic route the furan diepoxide is obtained through a one-step reaction starting from the furan dicarboxylic acid (FDCA) with epichlorohydrin. This protocol recalls the industrially optimized procedure for production of DGEBA, being performed through the condensation of FDCA with epichlorohydrin (ECH). This approach is remarkable, as biobased epichlorohydrin prepared from glycerol is already commercially available. ${ }^{28}$ The second synthetic route proposed is based on the transesterification between DM-FDCA and glycidol. DM-FDCA, obtained by esterification of FDCA, is a commercial compound used for the production of PEF. ${ }^{19,29}$

The reaction between FDCA and ECH to form BOFD proceeds through a mechanism similar to that recently reported by other authors for the acid moieties of vanillic and gallic acids $^{30-32}$ and represented in Scheme 1.

The reaction proceeds through the addition of the carboxylate group of FDCA to the epoxy ring of ECH. Experimental details are reported in "Synthesis procedures" Section in ESI. $\dagger$ As a first step of this procedure, FDCA is mixed with ECH in inert atmosphere in presence of the phase transfer catalyst tetrabutylammonium bromide (TBBr). The catalyst allows the

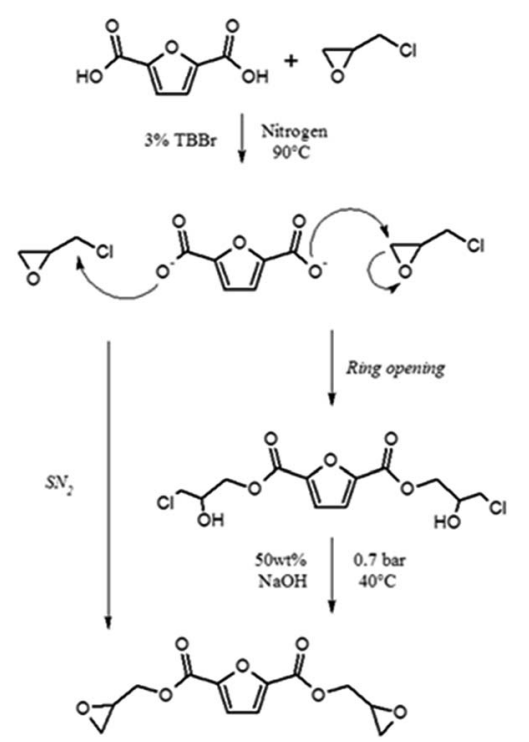

(a)

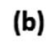

Scheme 1 Reaction mechanism in the glycidylation of FDCA. furan-2,5-dicarboxylate oxyanion to coexist with ECH, used also as solvent (Scheme 1a). The reaction proceeds directly with an SN2 mechanism or with a mechanism involving the opening of the epoxy ring that binds to the ion, resulting in the formation of the chlorohydrin intermediate represented in Scheme $1 \mathrm{~b} .^{33}$ Subsequently, cyclization of the chlorohydrin yields the glycidyl product (Scheme 1c). A preliminary TLC (hexane/ethyl acetate $1: 1)$ performed on the yellow viscous product showed the presence of at least six different compounds. Among them, oligomers and unreacted halohydrins could be detected by NMR analysis of the fractions obtained upon purification through column chromatography that resulted mandatory. In particular, several yellow and highly viscous fractions were obtained, except for BOFD, which was a white crystalline solid. To prove the occurrence of the condensation reaction between glycidyl group and FDCA, first FTIR-ATR and mono- and multidimensional ${ }^{1} \mathrm{H}$ and ${ }^{13} \mathrm{C}$-NMR analyses were carried out. FTIRATR spectra of FDCA and the purified BOFD are shown in Fig. 1.

The disappearance of the broad adsorption band due to $-\mathrm{OH}$ from carboxylic groups between 3200 and $2300 \mathrm{~cm}^{-1}$ correlated with the appearance of the strong ester band at $1709 \mathrm{~cm}^{-1}$ confirmed the conversion of carboxylic acids into ester moieties. The formation of the glycidyl group was confirmed by the appearance of the characteristic epoxy $\mathrm{C}-\mathrm{O}-\mathrm{C}$ absorption band at $902 \mathrm{~cm}^{-1}$ as well as of a peak at $1342 \mathrm{~cm}^{-1}$ related to the glycidyl methylene.

In Tables 1 and 2 are listed the characteristic FTIR bands of FDCA and BOFD, respectively.

To get a further insight on the structure of BOFD, NMR analysis was also performed through monodimensional ${ }^{1} \mathrm{H}$ and ${ }^{13} \mathrm{C}$ NMR spectroscopy to check the presence of the predicted structure and its purity. Fig. 2 displays the ${ }^{1} \mathrm{H}$-NMR spectrum of BOFD. The characteristic peaks of furanic proton at $7.27 \mathrm{ppm}$, overlapped with the signal of $\mathrm{CDCl}_{3}$, is visible in the figure inset; two double doublets at 4.65 and 4.20 , due to protons of methylene linked to the ester group, a sextet at $3.34 \mathrm{ppm}$ from methyne proton of oxirane ring, a triplet at 2.93-2.86 and a double doublet 2.73 due to protons of methylene on oxirane ring are also visible. These signals are in agreement with those reported in literature for the BOFD molecule obtained with a two-step procedure involving first the allylation of FDCA and the subsequent epoxidation of the double bond. ${ }^{24}$

${ }^{13} \mathrm{C}-\mathrm{NMR}$ spectrum of BOFD (Fig. 3) shows the peak at $157.73 \mathrm{ppm}$ corresponding to the ester carbon, the quaternary furanic carbon peak at $146.65 \mathrm{ppm}$, the $\mathrm{CH}$ furanic peak of

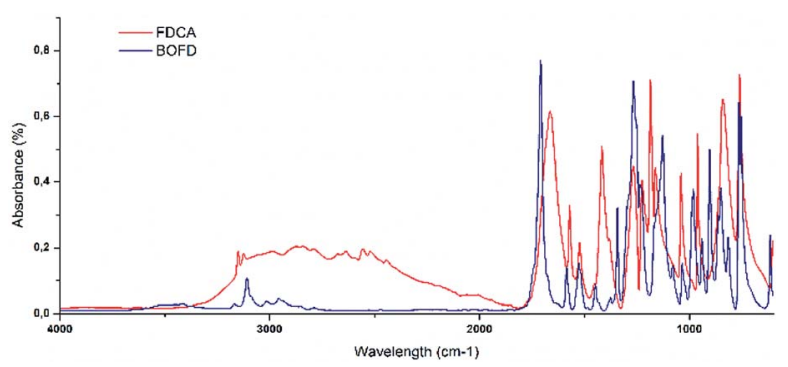

Fig. 1 FTIR spectra of FDCA and BOFD. 
Table 1 Peak assignments in FTIR spectrum of FDCA

\begin{tabular}{ll}
\hline Wavenumber $\left(\mathrm{cm}^{-1}\right)$ & Assignment \\
\hline $3151-2520$ & Stretching $\mathrm{O}-\mathrm{H}$ carboxylic acid \\
1665 & Stretching $\mathrm{C}=\mathrm{O}$ carbonyls \\
$1570-1416$ & Stretching $\mathrm{C}=\mathrm{C}$ aromatics (furan) \\
$1267-1039$ & Stretching C-O carboxylic acid \\
960 & Stretching $\mathrm{C}=\mathrm{O}, \mathrm{C}-\mathrm{C}-\mathrm{C}$ bending \\
& 2,5 sub-furan ring \\
$840-760$ & Bending C-H alkene (furan)
\end{tabular}

119.16 ppm, the glycidyl $\mathrm{CH}_{2}$ carbon peak at $66.16 \mathrm{ppm}$, and the peaks related to the $\mathrm{CH}$ and $\mathrm{CH}_{2}$ carbons of oxirane ring at 49.23 and $44.95 \mathrm{ppm}$, respectively. This spectrum is in agreement with that reported by Deng et al. ${ }^{24}$ The multiplicity of carbons to get the exact hydrogen-hydrogen and carbonhydrogen correlations, was determined by DEPT 90 and DEPT 135 analysis reported in ESI. $\dagger$ Moreover, multidimensional NMR analysis was also carried out through homonuclear correlation spectroscopy (COSY), heteronuclear single-quantum correlation spectroscopy (HSQC) and heteronuclear multiplebond correlation spectroscopy (HMBC), as reported in the ESI (Fig. 3S-6S $\dagger$ ).

Epoxy Equivalent Weight (EEW) was evaluated according to an alternative method proposed in literature, which relates the ratio between the peak intensity of epoxy and furanic ring protons in the ${ }^{1} \mathrm{H}$-NMR spectra, with the polymerization degree $n .^{34,35}$ In the specific case of BOFD, according to equation reported in "Methods" Section in ESI† the calculated was EEW $=152.41$, corresponding to a degree of polymerization $n=0.17$.

Transesterification of DM-FDCA with diols is part of an industrially optimized two-step procedure for the production of furanic/furanoate polyesters (followed by a polycondensation). ${ }^{19,36}$ This procedure requires high temperature (190-200 ${ }^{\circ} \mathrm{C}$ ) and the use of potentially toxic catalysts. ${ }^{37-39}$ In this paper, the synthesis is carried out at relatively low temperature $\left(60{ }^{\circ} \mathrm{C}\right)$ ("Synthesis procedures" Section in ESI $\dagger$ ). This is the maximum temperature that can be reached due to the high reactivity of glycidol, as it easily polymerizes, already at room temperature. An excess of glycidol was used in order to avoid as much as possible the formation of oligomers and a slight

Table 2 Peak assignment in FTIR spectrum of BOFD obtained by FDCA glycidylation

\begin{tabular}{|c|c|}
\hline Wavenumber $\left(\mathrm{cm}^{-1}\right)$ & Assignment \\
\hline $3165-2955$ & Stretching $\mathrm{C}-\mathrm{H}$ aromatics (furan) \\
\hline 1708 & Stretching $\mathrm{C}=\mathrm{O}$ ester \\
\hline 1585 to 1448 & Stretching $\mathrm{C}=\mathrm{C}$ aromatics (furan) \\
\hline $1375-1343$ & Bending $\mathrm{C}-\mathrm{H}, \mathrm{CH}_{2}$ of glycidyl \\
\hline $1267-1235$ & Stretching $\mathrm{C}-\mathrm{O}$ ester and epoxy ring \\
\hline $1127-1077$ & Stretching $\mathrm{C}-\mathrm{O}$ aromatic (furan) \\
\hline 1034-902 & Stretching $\mathrm{C}-\mathrm{O}$ epoxy ring \\
\hline $862-815$ & Stretching C-C epoxy ring \\
\hline $764-753$ & Rocking $\mathrm{C}-\mathrm{H}$ glycidyl \\
\hline
\end{tabular}

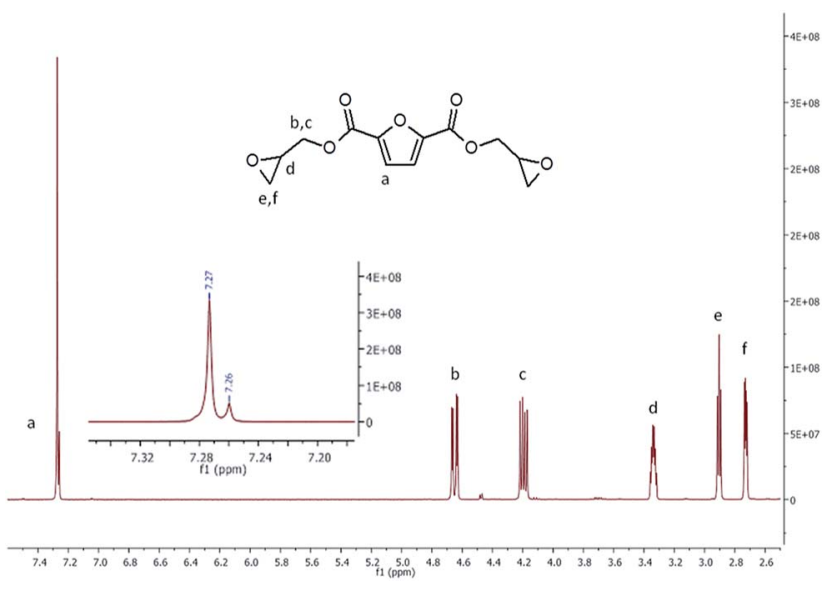

Fig. $2{ }^{1} \mathrm{H}-\mathrm{NMR}$ spectra of BOFD obtained by FDCA glycidylation.

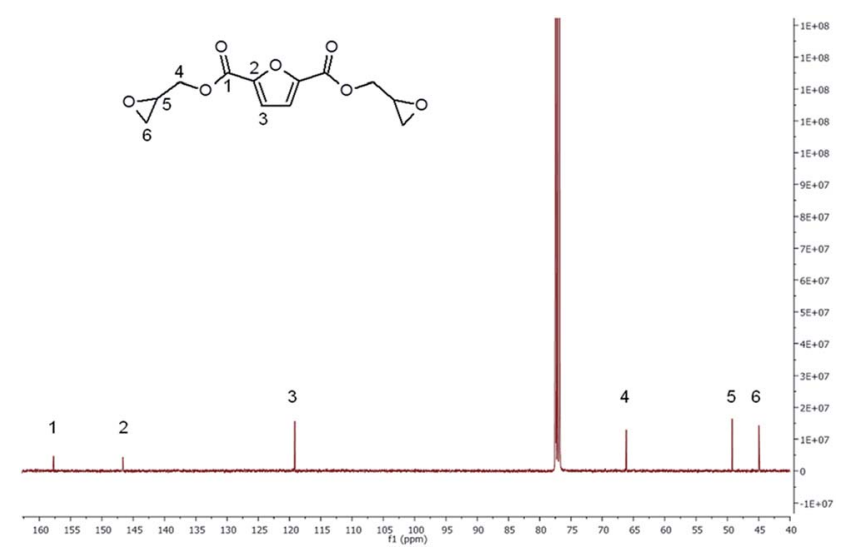

Fig. $3{ }^{13}$ C-NMR spectra of BOFD obtained by glycidylation.

vacuum was used in order to allow stripping of methanol produced during the reaction, yet hindering the volatile solvent evaporation. An improvement introduced by the proposed procedure is the use of a cheap, non-toxic catalyst, potassium cyanate (KOCN). The transesterification proceeded in a singlestep reaction sketched in Scheme 2 .

At room temperature, DM-FDCA and the catalyst were insoluble in the reaction mixture. However, heating resulted in a clear and transparent solution. The successful progress of the reaction was confirmed by the appearance of the mixture cooled down after 6 hours of reaction, which was viscous and transparent, with no evidence of precipitates. The so-obtained reaction mixture was extracted with a mixture of ethyl acetate and

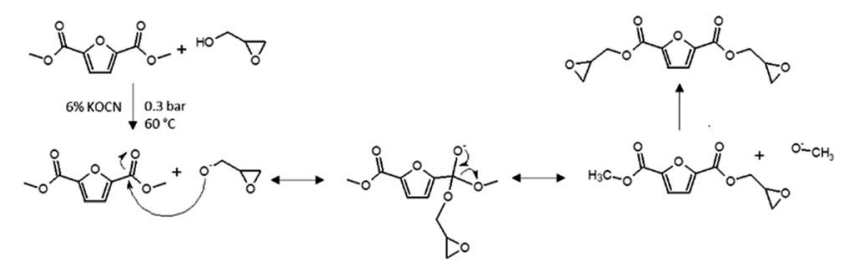

Scheme 2 Mechanism of transesterification of DM-FDCA with glycidol. 

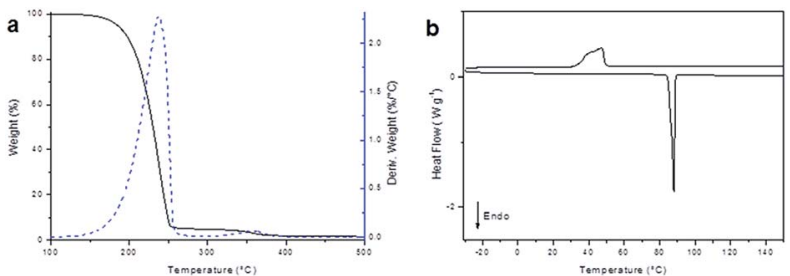

Fig. 4 (a) TGA analysis ( $10^{\circ} \mathrm{C} \mathrm{min}^{-1}$, under nitrogen), and (b) dynamic DSC analysis (heating-cooling cycle) of BOFD obtained by transesterification.

distilled water; in this way, the undesired by-products were dissolved in the aqueous phase, while the diglycidyl ester product was recovered in the organic. A further chromatographic purification was then performed to remove the residual unreacted DM-FDCA in the product. ${ }^{25,26,30,31,40}$

The conversion of DM-FDCA into BOFD was confirmed by FTIR-ATR and mono- and multi-dimensional ${ }^{1} \mathrm{H}$ and ${ }^{13} \mathrm{C}-\mathrm{NMR}$ analyses. Both FTIR-ATR and NMR spectra of BOFD obtained by transesterification present the same peaks as those of BOFD obtained by glycidylation. The spectrum of DM-FDCA and the table with peaks assignments are reported in the ESI. $\dagger$ As for the EEW calculation, in the case of BOFD obtained by transesterification, the degree of polymerization $n$, was 0.011 , providing also in this case a pure, low-molecular weight diepoxy compound, with EEW $=135,30$.

Once we proved the obtainment of the monomeric diglycidyl ester of furan, an accurate thermal characterization was carried out by thermogravimetric analysis (TGA) and differential scanning calorimetry (DSC), to determine the thermal stability, as well as melting and crystallization temperatures of the compounds. As can be noticed in TGA thermogram (Fig. 4a), BOFD resulted thermally stable up to $185^{\circ} \mathrm{C}$, when it lost $5 \%$ of the initial weight. At the end of this degradation step a total weight loss of $95 \%$ was measured. A further slight degradation step is visible at temperatures above $300{ }^{\circ} \mathrm{C}$, after which the residue at $650^{\circ} \mathrm{C}$ was $1 \%$. DSC analysis (Fig. 4b) showed a sharp endothermic peak associated to the melting process of BOFD at $88^{\circ} \mathrm{C}\left(\Delta H=112 \mathrm{~J} \mathrm{~g}^{-1}\right)$. During the cooling scan the occurrence of crystallization was evidenced by the presence of an exothermic peak having a maximum at $47{ }^{\circ} \mathrm{C}\left(91 \mathrm{~J} \mathrm{~g}^{-1}\right)$. The second heating scan overlapped the first scan. The sharpness of the endothermic peak was a further evidence of the compound purity.

\section{Conclusions}

In the present work, two new single-step synthetic routes are reported for the production of BOFD. Both approaches aim to limit the use of toxic reagents and propose low temperatures and short reaction times, with the easiness of the procedures based on fast, single-step procedures. FTIR-ATR, mono- and multi-dimensional analysis confirmed the structure expected for BOFD and evidenced a highly pure compound. Thermal properties of BOFD were determined through TGA and DSC analyses, which indirectly confirmed the purity of the compounds. In the present work, a proof of concept demonstrating the feasibility of simple and scalable routes to the synthesis of BOFD is provided. Further optimization of the presented synthesis protocols is needed to get higher reaction yields and consider these new procedures of great potential in actual applications.

\section{Conflicts of interest}

There are no conflicts to declare.

\section{Acknowledgements}

Alice Mija thanks RUDN University Program 5-100 for the financially support offered by the Ministry of Education and Science of The Russian Federation, agreement number 02.a03.0008.

\section{References}

1 S. Lambert and M. Wagner, Environmental performance of bio-based and biodegradable plastics: the road ahead, Chem. Soc. Rev., 2017, 46, 6855-6871.

2 A. Gandini, The irruption of polymers from renewable resources on the scene of macromolecular science and technology, Green Chem., 2011, 13, 1061-1083.

3 A. K. Mohanty, M. Misra and L. T. Drzal, Sustainable BioComposites from renewable resources: Opportunities and challenges in the green materials world, J. Polym. Environ., 2002, 10, 19-26.

4 R. Auvergne, S. Caillol, G. David, B. Boutevin and J. P. Pascault, Biobased thermosetting epoxy: Present and future, Chem. Rev., 2014, 114, 1082-1115.

5 B. S. Rubin, Bisphenol A: An endocrine disruptor with widespread exposure and multiple effects, J. Steroid Biochem. Mol. Biol., 2011, 127, 27-34.

6 S. G. Tan and W. S. Chow, Biobased Epoxidized Vegetable Oils and Its Greener Epoxy Blends: A Review, Polym.-Plast. Technol. Eng., 2010, 49, 1581-1590.

7 C. Zhang, T. F. Garrison, S. A. Madbouly and M. R. Kessler, Recent advances in vegetable oil-based polymers and their composites, Prog. Polym. Sci., 2017, 71, 91-143.

8 M. Pawar, A. Kadam, O. Yemul, V. Thamke and K. Kodam, Biodegradable bioepoxy resins based on epoxidized natural oil (cottonseed \& algae) cured with citric and tartaric acids through solution polymerization: A renewable approach, Ind. Crops Prod., 2016, 89, 434-447.

9 J.-M. Pin, N. Sbirrazzuoli and A. Mija, From epoxidized linseed oil to bioresin: An overall approach of epoxy/ anhydride cross-linking, ChemSusChem, 2015, 8, 1232-1243.

10 J.-M. Pin, N. Guigo, L. Vincent, N. Sbirrazzuoli and A. Mija, Copolymerization as a Strategy to Combine Epoxidized Linseed Oil and Furfuryl Alcohol: The Design of a Fully Bio-Based Thermoset, ChemSusChem, 2015, 8, 4149-4161.

11 T. Werpy and G. Petersen, Top Value Added Chemicals from Biomass. Volume I -Results of Screening for Potential Candidates from Sugars and Synthesis Gas, U. S. D. of Energy, 2004, DOI: 10.2172/926125. 
12 J. J. Bozell and G. R. Petersen, Technology development for the production of biobased products from biorefinery carbohydrates-the US Department of Energy's 'Top 10' revisited, Green Chem., 2010, 12, 539-554.

13 C. Yang and C. Huang, Biotransformation of 5-hydroxymethylfurfural into 2,5-furan-dicarboxylic acid by bacterial isolate using thermal acid algal hydrolysate, Bioresour. Technol., 2016, 214, 311-318.

14 A. Boisen, T. B. Christensen, W. Fu, Y. Y. Gorbanev, T. S. Hansen, J. S. Jensen, S. K. Klitgaard, S. Pedersen, A. Riisager, T. Ståhlberg and J. M. Woodley, Process integration for the conversion of glucose to 2,5furandicarboxylic acid, Chem. Eng. Res. Des., 2009, 87, 1318-1327.

15 X. Han, L. Geng, Y. Guo, R. Jia and X. Liu, Base-free aerobic oxidation of 5-hydroxymethylfurfural to 2,5furandicarboxylic acid over a $\mathrm{Pt} / \mathrm{C}-\mathrm{O}-\mathrm{Mg}$ catalyst, Green Chem., 2016, 18, 1597-1604.

16 N. Jiang, B. You, R. Boonstra, I. M. Terrero Rodriguez and Y. Sun, Integrating Electrocatalytic 5Hydroxymethylfurfural Oxidation and Hydrogen Production via Co-P-Derived Electrocatalysts, ACS Energy Lett., 2016, 1, 386-390.

17 F. Koopman, N. Wierckx, J. H. de Winde and H. J. Ruijssenaars, Efficient whole-cell biotransformation of 5-(hydroxymethyl) furfural into FDCA, 2,5furandicarboxylic acid, Bioresour. Technol., 2010, 101, 6291-6296.

18 G. Yi, S. P. Teong and Y. Zhang, Base-free conversion of 5hydroxymethylfurfural to 2,5-furandicarboxylic acid over a Ru/C catalyst, Green Chem., 2016, 18, 979-983.

19 G. Z. Papageorgiou, V. Tsanaktsis and D. N. Bikiaris, Synthesis of poly(ethylene furandicarboxylate) polyester using monomers derived from renewable resources: thermal behavior comparison with PET and PEN, Phys. Chem. Chem. Phys., 2014, 16, 7946-7958.

20 S. K. Burgess, J. E. Leisen, B. E. Kraftschik, C. R. Mubarak, R. M. Kriegel and W. J. Koros, Chain Mobility, Thermal, and Mechanical Properties of Poly(ethylene furanoate) Compared to Poly(ethylene terephthalate), Macromolecules, 2014, 47, 1383-1391.

21 M. Vannini, P. Marchese, A. Celli and C. Lorenzetti, Fully biobased poly(propylene 2,5-furandicarboxylate) for packaging applications: excellent barrier properties as a function of crystallinity, Green Chem., 2015, 17, 4162-4166.

22 Avantium, https:/www.avantium.com/press-releases/alplajoins-coca-cola-company-danone-avantiums-pef-bottledevelopment/.

23 J. T. Miao, L. Yuan, Q. Guan, G. Liang and A. Gu, Biobased Heat Resistant Epoxy Resin with Extremely High Biomass Content from 2,5-Furandicarboxylic Acid and Eugenol, ACS Sustain. Chem. Eng., 2017, 5(8), 7003-7011.

24 J. Deng, X. Liu, C. Li, Y. Jiang and J. Zhu, Synthesis and properties of a bio-based epoxy resin from 2,5furandicarboxylic acid (FDCA), RSC Adv., 2015, 5, 1593015939.
25 J. K. Cho, J. Lee, J. Jeong and B. Kim, Synthesis of carbohydrate biomass- based furanic compounds bearing epoxide end group (s) and evaluation of their feasibility as adhesives, J. Adhes. Sci. Technol., 2013, 27, 2127-2138.

26 F. Hu, J. J. La Scala, J. M. Sadler and G. R. Palmese, Synthesis and characterization of thermosetting furan-based epoxy systems, Macromolecules, 2014, 47, 3332-3342.

27 X. Shen, X. Liu, J. Wang, J. Dai and J. Zhu, Synthesis of an Epoxy Monomer from Bio-Based 2,5-Furandimethanol and Its Toughening via Diels-Alder Reaction, Ind. Eng. Chem. Res., 2017, 56, 8508-8516.

28 G. M. Lari, G. Pastore, C. Mondelli and J. Pérez-Ramírez, Towards sustainable manufacture of epichlorohydrin from glycerol using hydrotalcite-derived basic oxides, Green Chem., 2018, 20, 148-159.

29 G. Z. Papageorgiou, D. G. Papageorgiou, Z. Terzopoulou and D. N. Bikiaris, Production of bio-based 2,5-furan dicarboxylate polyesters: Recent progress and critical aspects in their synthesis and thermal properties, Eur. Polym. J., 2016, 83, 202-229.

30 M. Fache, R. Auvergne, B. Boutevin and S. Caillol, New vanillin-derived diepoxy monomers for the synthesis of biobased thermosets, Eur. Polym. J., 2015, 67, 527-538.

31 C. Aouf, S. Benyahya, A. Esnouf, S. Caillol, B. Boutevin and H. Fulcrand, Tara tannins as phenolic precursors of thermosetting epoxy resins, Eur. Polym. J., 2014, 55, 186-198.

32 C. Aouf, C. Le Guernevé, S. Caillol and H. Fulcrand, Study of the O-glycidylation of natural phenolic compounds. The relationship between the phenolic structure and the reaction mechanism, Tetrahedron, 2013, 69, 1345-1353.

33 M. Fache, E. Darroman, V. Besse, R. Auvergne, S. Caillol and B. Boutevin, Vanillin, a promising biobased building-block for monomer synthesis, Green Chem., 2014, 16, 1987-1998.

34 S. A. Garea, A. C. Corbu, C. Deleanu and H. Iovu, Determination of the epoxide equivalent weight (EEW) of epoxy resins with different chemical structure and functionality using GPC and 1H-NMR, Polym. Test., 2006, 25, 107-113.

35 F. G. Garcia and B. G. Soares, Determination of the epoxide equivalent weight of epoxy resins based on diglycidyl ether of bisphenol A (DGEBA) by proton nuclear magnetic resonance, Polym. Test., 2003, 22, 51-56.

36 G. Z. Papageorgiou, V. Tsanaktsis, D. G. Papageorgiou, S. Exarhopoulos, M. Papageorgiou and D. N. Bikiaris, Evaluation of polyesters from renewable resources as alternatives to the current fossil-based polymers. Phase transitions of poly(butylene 2,5-furan-dicarboxylate), Polymer, 2014, 55, 3846-3858.

37 J. Carlos Morales-Huerta, A. Martínez De Ilarduya and S. Muñoz-Guerra, Poly(alkylene 2,5-furandicarboxylate)s (PEF and PBF) by ring opening polymerization, Polymer, 2016, 87, 148-158.

38 J. Wang, X. Liu, Y. Zhang, F. Liu and J. Zhu, Modification of poly(ethylene 2,5-furandicarboxylate) with 1,4cyclohexanedimethylene: Influence of composition on mechanical and barrier properties, Polymer, 2016, 103, 1-8. 
39 L. G. Voskressensky, O. A. Storozhenko, A. A. Festa, R. A. Novikov and A. V. Varlamov, Synthesis of Chromenoimidazoles, Annulated with an Azaindole Moiety, through a Base-Promoted Domino Reaction of Cyanomethyl Quaternary Salts, Synthesis, 2017, 49, 27532760.
40 Z. Rapi, B. Szolnoki, P. Bakó, P. Niedermann, A. Toldy, B. Bodzay, G. Keglevich and G. Marosi, Synthesis and characterization of biobased epoxy monomers derived from d-glucose, Eur. Polym. J., 2015, 67, 375-382. 